\title{
Detection of Poxvirus in Cattle Associated with Human Cases in the State of Rio de Janeiro: Preliminary Report
}

\author{
Hermann Gonçalves Schatzmayr, Elba Regina Sampaio de Lemos ${ }^{+}$, \\ Carlos Mazur**, Armando Schubach*, Selma Majerowicz, Tatiana Rozental, \\ Tânia Maria Pacheco Schubach*, Maria Cristina Bustamante***, \\ Ortrud Monika Barth
}

\begin{abstract}
Departamento de Virologia, Instituto Oswaldo Cruz *CPq Hospital Evandro Chagas-Fiocruz, Av. Brasil 4365, 21045-900 Rio de Janeiro, RJ, Brasil **Departamento de Microbiologia e Imunobiologia Veterinária,

Universidade Federal Rural do Rio de Janeiro, Seropédica, Rio de Janeiro, RJ, Brasil

***Secretaria Municipal de Saúde de Piraí, Piraí, RJ, Brasil
\end{abstract}

This preliminary report describes human and cow cases of poxvirus that recently ocurred in the State of Rio de Janeiro. The electron microscopic findings were consistent with parapoxviral and orthopoxviral infection. Orthopoxvirus strains were isolated from human and cow cases. Detailed viral characterization by means of genetical techniques is under investigation. Based on these informations, poxviral diseases should be also considered an emerging viral zoonosis that can affect human beings.

Key words: poxvirus - human disease - cattle - electron microscopy - Brazil

The poxviral diseases of man consist of several clinical entities caused by viruses of the family Poxviridae, subfamily Chordopoxvirinae, which includes the genera Orthopoxvirus (smallpox, vaccinia, monkeypox and cowpox viruses), Parapoxvirus (orf, milker's nodes, pseudocowpox and sealparapox viruses), Yatapoxvirus (yatapox and tanapox) and Molluscipoxvirus (molluscum contagiosum virus).

Poxvirus diseases, in general, are acute with no strong evidence for latent, persistent, or chronic infections. They can be localized or systemic and infect their hosts by all possible routes, through the skin by mechanical means, via the respiratory tract, or by the oral route.

Parapoxvirus genus members are distributed worldwide and are carried by beef and dairy cattle, sheep, goats, camelides and other animals. The disease in humans is an accident with development of lesions characterized by papules, nodules and rarely vesicles, pustules and ulcers on the

\footnotetext{
${ }^{+}$Corresponding author. Fax: +55-21-270-6397. E-mail: erslemos@gene. dbbm.fiocruz.br

Received 22 December 1999

Accepted 7 April 2000
}

hands, arms, face, among other sites of viral inoculation (Fenner 1996, Kuroda et al. 1999). Fever and lymphangitis/lymphadenitis occur occasionally and dermal lesions are sometimes mistaken for abscesses, mainly when secondary bacterial infection occurs, making the diagnosis difficult.

Parapoxviruses are DNA viruses of 250/300 nm long by $150 / 190 \mathrm{~nm}$ wide. Their characteristic surface pattern of a regular criss-cross spiral arrangement of a single continous thread enables the identification by electron microscopy (EM), (Doane \& Anderson 1987, Madeley \& Field 1988). The diagnosis can be also established on the basis of ELISA, immunofluorescence and Western blot tests, DNA assay and viral growth in cell cultures.

In the orthopoxvirus group, besides smallpox already eradicated, monkeypox, cowpox and vaccinia viruses among others, can cause human infections. Monkeypox and cowpox are restricted geographically because of limited ability to adapt beyond the indigenous animal reservoir, which comprises certain rodent species (Fenner 1996). Several cases of orthopoxviruses have been described in different regions of the World and recently orthopoxvirus-like viruses, not yet fully characterized, have been reported in Germany (Munz et al. 1992, Czerny et al. 1997) and Israel (Yeruham et al. 1996). The molecular analysis of 
several strains isolated in the World has demonstrated that the orthopoxvirus found in the Americas is very different from the old world orthopoxvirus, suggesting long term separation of lineages (Fenner 1996).

Humans may be infected by contact with the wildlife source or by infected animals of several species as rodents or cats (Fenner 1996).

Only smallpox and monkeypox have been known as generalized human diseases. Cowpox and vaccinia cause, generally, localized, and pustular lesions with lymphodenopaty. Rarely secondary lesions can occur and immunologic deficiencies should be considered (Fenner 1996, Czerny et al. 1997).

Orthopoxviruses are DNA viruses and can be identified by EM. They are large and brick shaped virions of 220-450 $\mathrm{nm}$ long by $140-260 \mathrm{~nm}$ wide, presenting an irregularly structured surface pattern. Other laboratory methods described previously for the parapoxvirus group can also be used for viral diagnosis (Doane \& Anderson 1987, Madeley \& Field 1988).

In April 1999, four patients developed papules, vesicles and pustules after exposure to similar lesions on cow's teats in a farm in Piraí county, State of Rio de Janeiro. On the 3rd week of illness, one of the patients was referred to Evandro Chagas Hospital-Fiocruz and samples for dermal scraping were obtained, although the skin lesions had healed. Unfortunately, virus particles from this unique patient sample could not be detected by EM techniques. Staphilococcus aureus was isolated and probably this bacterial contamination influenced the lack of diagnosis confirmation in human case. Simultaneously, one of the authors collected dermal lesion specimens and scabs from infected cows. The analysis by EM showed particles presenting characteristic structures of parapoxvirus in this material (Fig. 1).

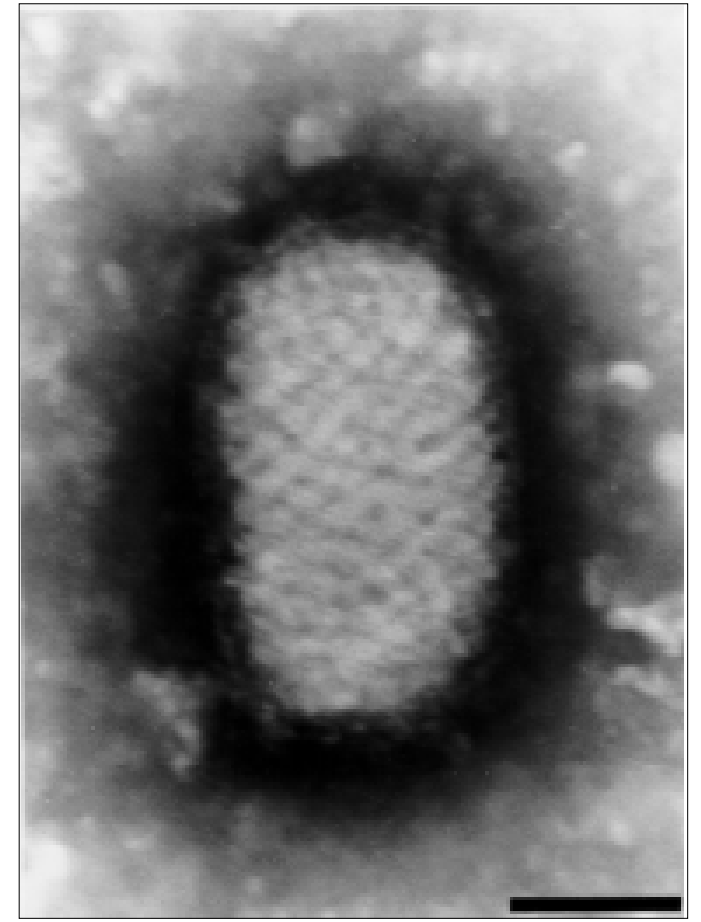

Fig. 1: parapoxvirus identified by electron microscopy in cow's teat lesions, in a farm in Piraí County, RJ. Bar $=100$ $\mathrm{nm}$

Four months after the parapoxviral cases in Piraí, ten patients that lived in counties on north of the state showed lesions characterized by vesicles, pustules, ulcers on different sites (Table). All of them were males and had history of contact with cattle. During the outbreak, three of the authors visited the county of Cantagalo and found cows with lesions on teats and three human cases with lesions on healing stage. Brick-shaped particles compatible with orthopoxvirus was demonstrated by EM (Fig. 2). Virus isolation was suc-

TABLE

Orthopox infection in humans reported in the State of Rio de Janeiro

\begin{tabular}{cclclcc}
\hline Patient & Age & Locality & Date & Sites of lesions & EM & Culture \\
\hline 01 & 20 & Cantagalo & $8 / 2$ & Hand & ND & ND \\
02 & WI & Cantagalo & $8 / 9$ & Hand & ND & ND \\
03 & WI & Cantagalo & $8 / 13$ & Hand & ND & ND \\
04 & 15 & Cantagalo & $8 / 20$ & Hand & ND & ND \\
05 & 50 & Cantagalo & $9 / 14$ & Hand & ND & ND \\
$06^{a}$ & 23 & Cantagalo & $9 / 14$ & Face, hand, escrotum & ND & ND \\
07 & 20 & Cantagalo & $9 / 14$ & Leg & ND & ND \\
08 & 16 & Cantagalo & $9 / 18$ & Leg & ++++ & ++++ \\
09 & 15 & Cantagalo & $10 / 14$ & Hand, arm & Hand & ++++ \\
10 & WI & S. Antônio Pádua & $10 / 22$ & ++++ \\
\hline
\end{tabular}

$a$ : fever and myalgia; ND: not done; EM: electron microscopy; WI: without information 


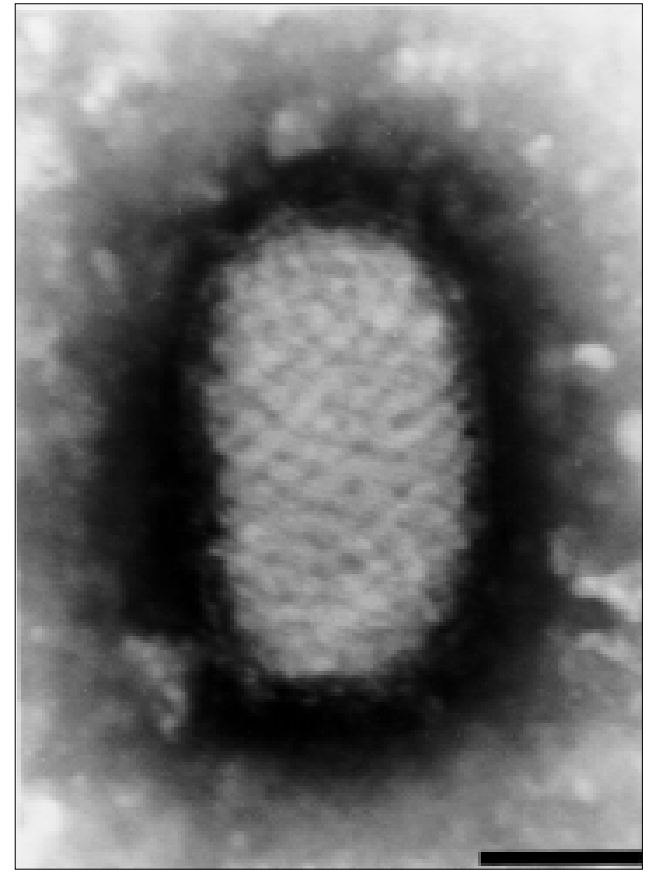

Fig. 2: orthopoxvirus identified by electron microscopy in dermal lesion samples collected from human being, in Santo Antônio de Pádua county, RJ. Bar = 100 nm

cessful in Vero cell culture of samples from two patients from Cantagalo and Santo Antônio de Pádua counties. In the counties of Aperibé and Cambuci, only samples from infected cows were obtained and one of these cases, an orthopoxvirus virus strain could be isolated in Vero cell culture. More information will be reported after viral genetical identification.

In this preliminary study, the presence of poxviruses in cows associated with compatible human cases, emphasizes the need of surveillance for the presence of different zoonosis that can occasionally affect human beings.

\section{REFERENCES}

Czerny CP, Zeller-Lue C, Eis-Hubinger AM, Kaaden OR, Meyer H 1997. Characterization of a cowpoxlike orthopox virus which had a lethal infection in man. Arch Virol (Suppl.) 13: 13-24.

Doane FW, Anderson N 1987. Electron Microscopy in Diagnostic Virology, Cambridge University Press, $178 \mathrm{pp}$.

Fenner F 1996. Poxvirus. In BN Fields, Fields Virology, Lippincott-Raven Publishers, Philadelphia, p. 2673-2695.

Kuroda Y, Yoshida M, Shibahara T, Matsui T, Nakane T, Hara H, Inoshima Y, Sentsui 1999. An epidemic of parapoxvirus infection among cattle: isolation and antibody survey. J Vet Med Sci 61: 749-753.

Madeley CR, Field AM 1988. Virus Morphology, Churchill Livingstone, Edinburgh, 295 pp.

Munz E, Linckh S, Renner-Muller IC 1992. Infections with original cowpox virus and cowpox-like agents in human and animals: a literature review. Zentralbl Veterinarmed 39: 209-225.

Yeruham I, Nyska A, Abraham A, Algazi R 1996. Occurence of cowpox-like lesions in cattle in Israel. Rev Elev Med Vet Pays Trop 49: 299-302. 
